Check for updates

Cite this: J. Mater. Chem. A, 2019, 7, 25521

Received 11th July 2019

Accepted 16th September 2019

DOI: $10.1039 / \mathrm{c} 9 \mathrm{ta0} 5510 \mathrm{k}$

rsc.li/materials-a

\section{Efficient separation of propane and propene by a hypercrosslinked polymer doped with $\mathrm{Ag}(1) \dagger$}

\author{
Andrew Stephenson, $\$^{a}$ Buyi Li, $\neq^{a}$ Linjiang Chen, (D) $\neq^{\mathrm{ab}}$ Rob Clowes, ${ }^{a}$ Michael E. Briggs ${ }^{a}$ \\ and Andrew I. Cooper (D)*ab
}

Porous hypercrosslinked polymers (HCPs) are attractive for large-scale separations because they are inexpensive, robust, scalable, and easy to functionalize. Here, we describe a series of microporous HCPs that were derivatized with sulfonic acid groups, then doped with silver (Ag(I)). The Ag-doped HCPs show a high selectivity towards olefins over paraffins, which is one of the most energy-intensive separations in the chemical industry. The separation capability of the HCP can be enhanced by fine-tuning the amount of $\mathrm{Ag}(\mathrm{I})$ in the HCP. Breakthrough measurements confirm excellent separation of propane and propene under flow conditions at $298 \mathrm{~K}$ and at $318 \mathrm{~K}$. Metal-doped HCPs might lead in the future to a large energy savings compared to other energy-intensive gas separation methods such as distillation.

\section{Introduction}

The separation of olefins and paraffins is one of the most important processes in the chemical industry. Feedstocks of pure ethene and propene are required for the synthesis of polyethylene and polypropylene, respectively, with more than 200 million tonnes produced annually. ${ }^{1}$ The purification of olefins is energy intensive because the components being separated are chemically and physically very similar. As a result, olefin purification accounts for $0.3 \%$ of the world's total energy use. At present, the separation method most commonly employed by industry is cryogenic distillation, which requires large amounts of energy for the cooling and compression of gases. For example, propane and propene separation is normally carried out at $243 \mathrm{~K}$ and 30 bar. $^{2}$

Much research has focussed on developing adsorptive separations that might offer cheaper and less energy-intensive routes for olefin separation. ${ }^{3}$ Examples of adsorptive separations of olefins and paraffins have been demonstrated using metal-organic frameworks (MOFs), ${ }^{4-8}$ zeolites, ${ }^{9,10}$ and activated carbons. ${ }^{11}$ Due to similarities in the shape and size of propane and propene, molecular sieving has proved difficult to achieve. However, MOFs with precisely-tuned pores were recently shown to selectively adsorb propene with the exclusion of propane ${ }^{12}$ and ethene with the exclusion of ethane. ${ }^{13} \mathrm{~A}$ more common

${ }^{a}$ Department of Chemistry and Materials Innovation Factory, University of Liverpool, Liverpool, $U K$

${ }^{b}$ Leverhulme Research Centre for Functional Materials Design, Materials Innovation Factory and Department of Chemistry, University of Liverpool, Liverpool, UK. E-mail: aicooper@liverpool.ac.uk

$\dagger$ Electronic supplementary information (ESI) available. See DOI: 10.1039/c9ta07510k

\$ These authors contributed equally. approach has been to use open metal sites; for example in MOFs $^{14-16}$ or in metal-doped materials. Ag(I) has previously been loaded into sulfonic acid decorated $\mathrm{MOFs}^{17}$ and $\mathrm{PAFs}^{18}$ and applied to olefin/paraffin separation. The double bond present in olefins is able to form a $\pi$-complex with the open metal sites whereas paraffins are only able to form much weaker van der Waals interactions. ${ }^{19}$ This results in a difference in affinity between the two guest molecules, which can be used to perform the separation. To be industrially useful, the interaction must be strong enough to allow good separation of the two gases, but not so strong that removing the adsorbed propene is difficult and energy intensive. Ideally, the separation will be performed at ambient temperature and pressure, with easy desorption of the gases and good recyclability of the material. In order to be suitable for polypropylene production, for example, the propene recovered from the separation must be $>99 \%$ pure. Less pure propene could be used as a 'chemical-grade' reagent or it could be part of a hybrid separation process where the bulk separation is performed by adsorption and then the final product is polished by cryogenic distillation. Such hybrid methods might still more than halve the energy used for propene production. ${ }^{1}$ Ideally, sorbents for such large scale gas separation processes should be inexpensive and robust, which prompted us to investigate hypercrosslinked polymers (HCPs).

\section{Results}

HCPs are robust microporous materials that can have a range of surface areas and possess various functionalities. ${ }^{20}$ Importantly, HCPs are cheap to produce and are scalable, making them attractive substrates for large-scale separations. HCPs can be prepared via a Friedel-Crafts reaction with $\mathrm{FeCl}_{3}$ using formaldehyde dimethylacetal (FDA) as the cross-linker. In this study, 
a number of benzene-based HCPs were synthesized and functionalized with sulfonic acid groups. By varying the ratio of FDA crosslinker to benzene, three benzene-based HCPs with different surface areas were synthesized, HCP-(1-3) (Scheme 1). Upon treatment with chlorosulfonic acid, differences in the number of accessible benzene sites in each polymer led to varying proportions of sulfonation. The sulfonated HCPs were then impregnated with $\mathrm{Ag}(\mathrm{I})$ by soaking in a silver nitrate solution (Scheme 1). Hence, by varying the amount of crosslinker to monomer in the synthesis of the HCP, the amount of $\operatorname{Ag}(\mathrm{I})$ can be fine-tuned to optimise performance for the separation. It is expected that the combination of microporosity and $\mathrm{Ag}(\mathrm{I})$ ions should give the HCP excellent olefin/paraffin separation ability. Whilst the incorporation of more $\operatorname{Ag}(\mathrm{I})$ sites should result in a stronger affinity with olefins compared to paraffins, it can also reduce the surface area and pore volume of the HCPs and therefore their uptake capacity. HCP-Ag-1, HCP-Ag-2, and HCP-Ag-3 were synthesized with 1.21, 1.77 , and $2.58 \mathrm{mmol} \mathrm{g}^{-1}$ of $-\mathrm{SO}_{3} \mathrm{Ag}$, respectively.

Nitrogen sorption isotherms for the unfunctionalized, sulfonated, and Ag(I)-doped HCPs were measured at $77 \mathrm{~K}$ (Fig. 1) and the apparent BET surface areas $\left(\mathrm{SA}_{\mathrm{BET}}\right)$ were calculated (Table 1). HCP-1 and HCP-2 have similar SA $\mathrm{BET}_{\mathrm{BET}}$ values of 1350 and $1376 \mathrm{~m}^{2} \mathrm{~g}^{-1}$, respectively. HCP-3, which uses the lowest ratio of FDA crosslinker to benzene, has the lowest surface area of $823 \mathrm{~m}^{2} \mathrm{~g}^{-1}$. Although HCP-3 has the lowest proportion of crosslinking and consequently the lowest surface area, it has more available non-crosslinked aromatic sites for postfunctionalization, which results in SAM-HCP-3 and SAM-HCP$\mathrm{Ag}-3$ having the highest concentration of sulfonic acid groups and highest Ag(I) loading, respectively. SAM-HCP-Ag-1 and SAMHCP-Ag-2 have moderate surface areas of 285 and $261 \mathrm{~m}^{2} \mathrm{~g}^{-1}$, respectively, after metalation whereas SAM-HCP-Ag-3 has a much lower $\mathrm{SA}_{\mathrm{BET}}$ of $7 \mathrm{~m}^{2} \mathrm{~g}^{-1}$ and is essentially non-porous to $\mathrm{N}_{2}$ at $77 \mathrm{~K}$. This suggests that the additional Ag(I) in SAM-HCP$\mathrm{Ag}-3$ is blocking access to the pore network and preventing the adsorption of $\mathrm{N}_{2}$ molecules at $77 \mathrm{~K}$.

Propane and propene sorption isotherms were measured up to 1 bar for the three Ag(I) doped HCPs at 273 and at 298 K (Fig. 2a). All three HCPs take up more propene than propane at 1 bar although by varying degrees. SAM-HCP-Ag-1, the HCP with the lowest loading of $\mathrm{Ag}(\mathrm{I})$, only takes up $0.2 \mathrm{mmol} \mathrm{g}^{-1}$ more propene

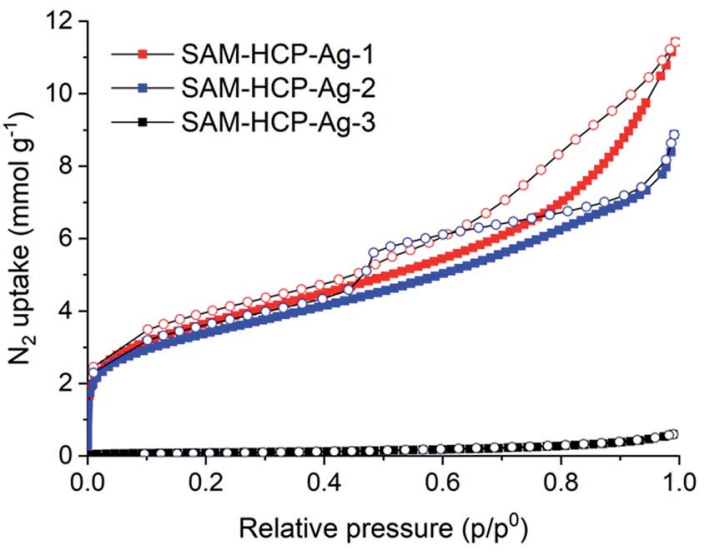

Fig. 1 Nitrogen sorption isotherms of SAM-HCP-Ag-(1-3) at $77 \mathrm{~K}$. Closed and open symbols represent adsorption and desorption isotherms, respectively.

than propane at 1 bar and at lower pressures this difference is even smaller. Based on the single component isotherms, SAM-HCP-Ag-1 does not seem like a good candidate for propane/propene separation. SAM-HCP-Ag-2 has the highest uptake of propene at 1 bar and $298 \mathrm{~K}\left(1.85 \mathrm{mmol} \mathrm{g}^{-1}\right)$ although it does also have a relatively high uptake of propane of $\sim 1 \mathrm{mmol} \mathrm{g}^{-1}$. SAM-HCP-Ag-3, which was essentially non-porous to $\mathrm{N}_{2}$ at $77 \mathrm{~K}$ has a slightly lower propene uptake than SAM-HCP-Ag-2 at 1 bar of $1.75 \mathrm{mmol} \mathrm{g}^{-1}$. The uptake of propane by SAM-HCP-Ag-3 is far lower, only $0.5 \mathrm{mmol}$ $\mathrm{g}^{-1}$ at 1 bar, presumably due to the low surface area of the HCP and the absence of $\pi$-interactions between propane and $\mathrm{Ag}(\mathrm{I})$.

Looking at the single component isotherms, we decided that SAM-HCP-Ag-3 might have the most promise for propane/ propene separation, despite its low surface area. This was confirmed by its high propene/propane selectivity (Fig. 3), as calculated using the ideal adsorbed solution theory (IAST): SAMHCP-Ag-3 showed a high selectivity, at $298 \mathrm{~K}$ and 1 bar, of 24 and 65 for $50: 50$ and 10:90 propene/propane mixtures, respectively. This is comparable with the best-performing materials in the literature and, to our knowledge, this makes SAM-HCP-Ag-3 the best performing organic polymer reported to date (Table $\mathrm{S} 1 \dagger$ ). The selectivity at lower pressures was calculated to be even higher.

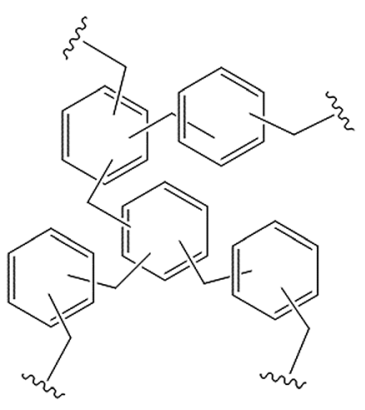

HCP-(1-3)

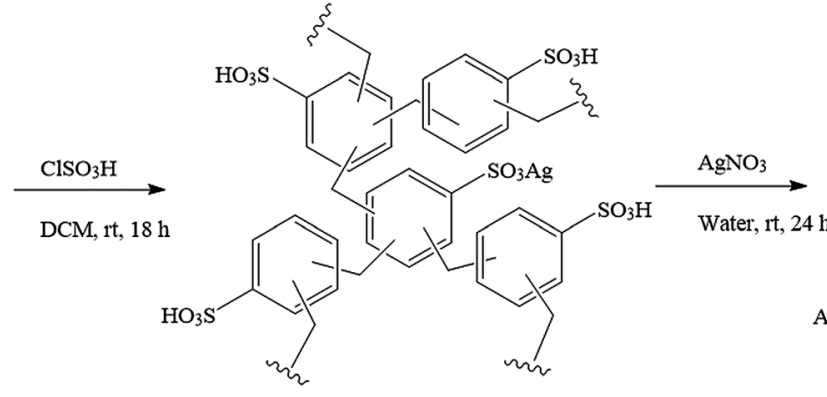

SAM-HCP-(1-3)

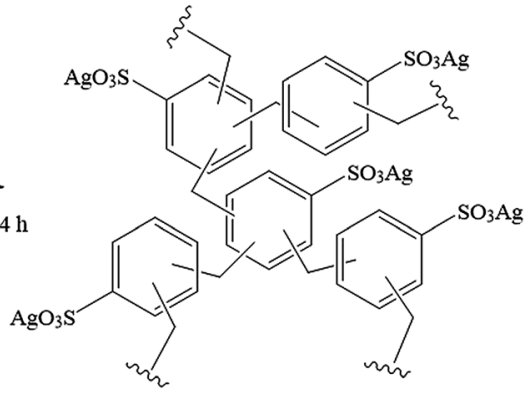

SAM-HCPs-Ag-(1-3)

Scheme 1 Synthesis of SAM-HCP-Ag-1, SAM-HCP-Ag-2, and SAM-HCP-Ag-3. The ratio of crosslinker (FDA) to monomer (benzene) decreases in the series HCP-(1-3) (see ESI†). 
Table 1 Surface area and elemental analysis of the parent, sulfonated, and Ag(I)-doped HCPs

\begin{tabular}{lllllll}
\hline Sample & $\mathrm{SA}_{\mathrm{BET}}\left(\mathrm{m}^{2} \mathrm{~g}^{-1}\right)$ & $\mathrm{C}$ & $\mathrm{H}$ & $\mathrm{S}$ & $-\mathrm{SO}_{3} \mathrm{H}\left(\mathrm{mmol} \mathrm{g}^{-1}\right)$ & $-\mathrm{SO}_{3} \mathrm{Ag}^{a}\left(\mathrm{mmol} \mathrm{g}^{-1}\right)$ \\
\hline HCP-1 & 1350 & 82.05 & 5.20 & - & - & - \\
HCP-2 & 1376 & 85.32 & 5.55 & - & - & - \\
HCP-3 & 823 & 89.91 & 5.72 & - & - & - \\
SAM-HCP-1 & 889 & 63.86 & 4.80 & 4.14 & 1.29 & - \\
SAM-HCP-2 & 948 & 60.80 & 4.76 & 5.48 & 1.71 & - \\
SAM-HCP-3 & 511 & 61.66 & 4.60 & 10.01 & 3.12 & 1.21 \\
SAM-HCP-Ag-1 & 285 & 52.48 & 3.97 & 2.90 & - & 1.77 \\
SAM-HCP-Ag-2 & 261 & 52.64 & 3.87 & 3.80 & - & \\
SAM-HCP-Ag-3 & 7 & 43.18 & 3.44 & 6.57 & - &
\end{tabular}

${ }^{a}$ The amounts of silver were tested by atomic absorption spectroscopy after microwave digestion.
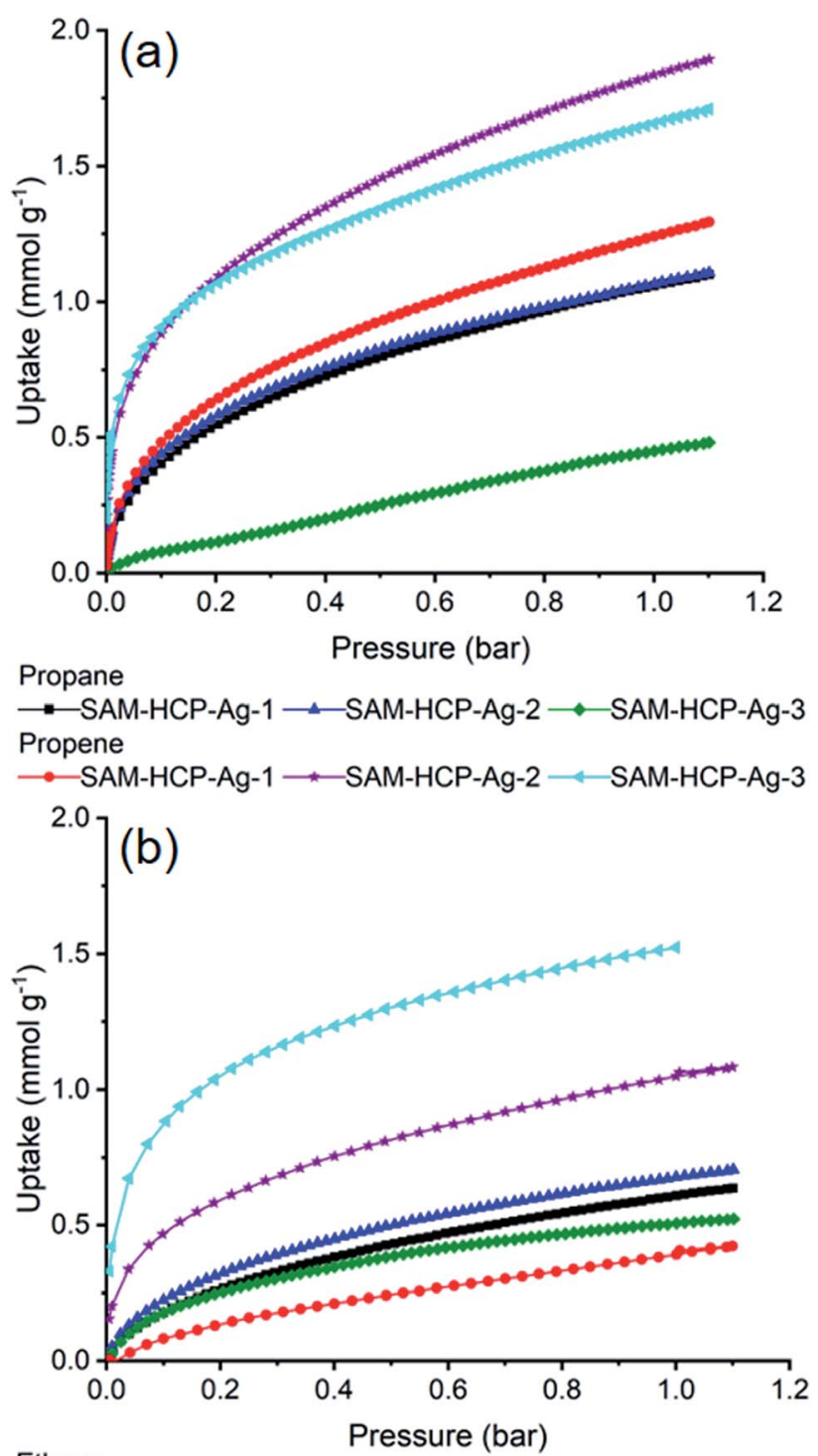

Ethane

$\longrightarrow$ SAM-HCP-Ag-1 $\longrightarrow$ SAM-HCP-Ag-2 $\multimap$ SAM-HCP-Ag-3 Ethene

$\longrightarrow$ SAM-HCP-Ag-1 \#SAM-HCP-Ag-2 «SAM-HCP-Ag-3

Fig. 2 Propane/propene adsorption isotherms (a) and ethane/ethene adsorption isotherms (b) for SAM-HCP-Ag-(1-3) at $298 \mathrm{~K}$.

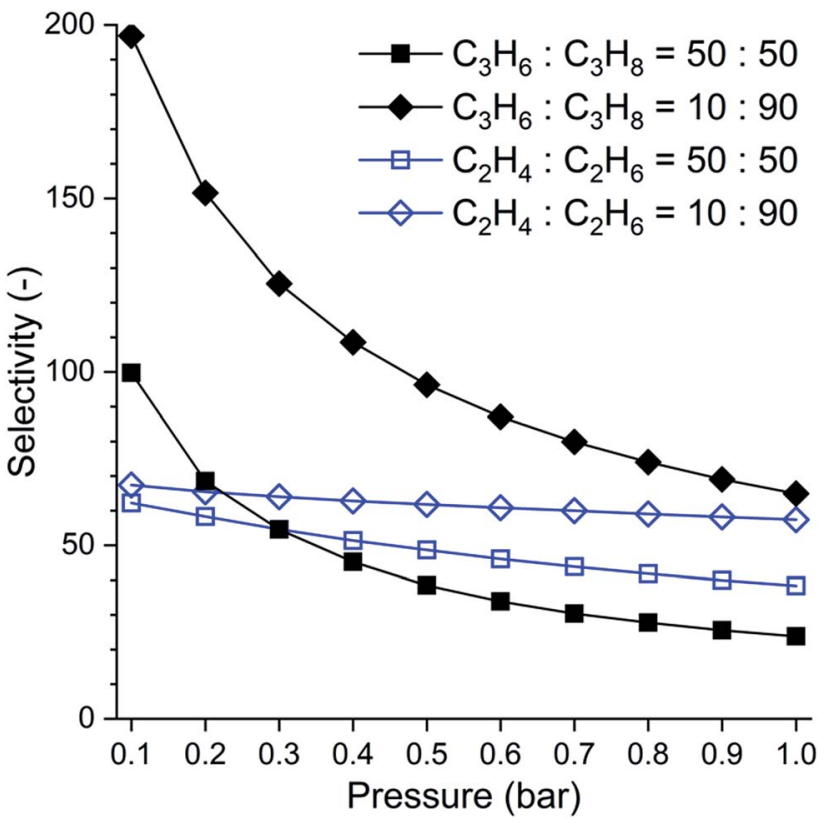

Fig. 3 Pressure-dependent IAST selectivity of propene $\left(\mathrm{C}_{3} \mathrm{H}_{6}\right)$ over propane $\left(\mathrm{C}_{3} \mathrm{H}_{8}\right)$ and that of ethene $\left(\mathrm{C}_{2} \mathrm{H}_{4}\right)$ over ethane $\left(\mathrm{C}_{2} \mathrm{H}_{6}\right)$ determined for SAM-HCP-Ag-3 with two gas mixture ratios, using experimental isotherms at $298 \mathrm{~K}$ (Fig. 2).

Ethane and ethene gas sorption isotherms were also measured (Fig. 2b) for the Ag-doped HCPs. Again, SAM-HCP-Ag3 shows the most promise for separation of these two gases, and the uptakes of ethane and ethene were similar to those observed for the propane/propene gas pair. For SAM-HCP-Ag-2 and SAMHCP-Ag-1, there is a large drop in uptake of ethene compared to propene; SAM-HCP-Ag-1 actually adsorbs more ethane than ethene. IAST selectivities of ethene over ethane show that SAMHCP-Ag-3 has the potential to perform a separation of these two gases (Fig. 3). The IAST selectivity was calculated to be 38 and 57 for $50: 50$ and $10: 90$ ethene/ethane mixtures, respectively, at $298 \mathrm{~K}$ and 1 bar. These IAST selectivities are amongst the highest values reported, although the absolute uptake of ethene $\left(1.5 \mathrm{mmol} \mathrm{g}^{-1}\right)$ at 1 bar is lower than many other materials reported in the literature (Table $\mathrm{S} 2 \dagger$ ), and hence one would expect SAM-HCP-Ag-3 to have a relatively low working capacity. 
In order to test whether the IAST olefin/paraffin selectivity could be realised in practice, we conducted breakthrough experiments with a propene/propane gas mixture flowing through a fixed bed of SAM-HCP-Ag-3 (see ESI $\dagger$ for experimental details). Breakthrough curves give a more realistic picture of the separation potential of a material than IAST calculations, because the separation under breakthrough conditions also requires good kinetics, something not accounted for in the IAST selectivities.

The results from the breakthrough of a 50:50 propene/ propane mixture are shown in Fig. 4a. Propane breaks through the column first as expected and has the characteristic 'roll up' until the propene breaks through approximately 15 minutes later (Fig. S10†). Fig. 4 shows the outlet gas composition from the point at which propane first breaks through; the propane has a $>99 \%$ purity for approximately 15 minutes, as determined by the mass spectrometer. Capacities for the material are calculated as 0.95 and $0.29 \mathrm{mmol} \mathrm{g}^{-1}$ for propene and propane, respectively. This gave a calculated selectivity of 3.3, lower than predicted by IAST calculations. However, it is still clear that the material does separate the propane and propene very efficiently under the kinetic conditions of the breakthrough experiment.

The results from the breakthrough measurements for a $10: 90$ propene/propane mixture are shown in Fig. 4b. The outlet composition shows that the effluent has a $>99 \%$ purity of propane for approximately 175 minutes as determined by the mass spectrometer. Capacities for the material under these conditions were calculated to be 0.70 and $0.54 \mathrm{mmol} \mathrm{g}^{-1}$ for propene and propane, respectively. This gave a calculated selectivity of 11.7, again lower than that predicted by IAST calculations. With a separation of approximately 175 minutes between the two gases breaking through, it is clear that the material is also effective at separating propene from propane at lower concentrations.

It has been argued that $318 \mathrm{~K}$ might be the optimal temperature for the practical separation of hydrocarbons; ${ }^{14}$ we therefore also repeated the breakthrough experiment at this temperature (Fig. S11†). The capacities were only slightly lower than at $298 \mathrm{~K}$; 0.88 and $0.27 \mathrm{mmol} \mathrm{g}^{-1}$ for propene and propane, respectively.

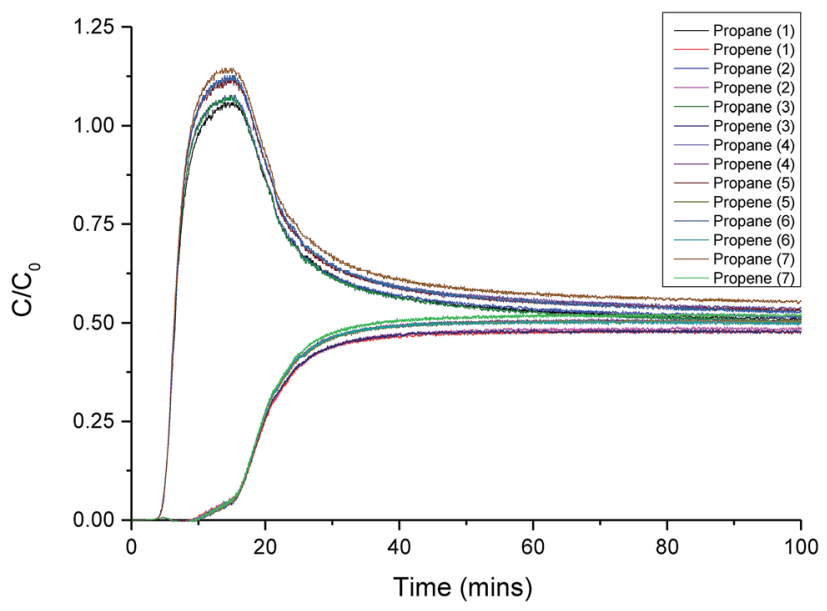

Fig. 5 Overlay of seven repeat breakthrough curves of $50: 50$ propane/propene flowing through a bed of SAM-HCP-Ag-3. The total flow rate was $3 \mathrm{~mL} \mathrm{~min}{ }^{-1}$ at $298 \mathrm{~K}$ and $500 \mathrm{mbar}$. Time 0 is when the propane/propene mixture starts flowing through the column.

Importantly, at this higher temperature, the selectivity remains unchanged with a value of 3.3. This shows good potential for using SAM-HCP-Ag-3 as a material in practical applications at $318 \mathrm{~K}$.

For real applications, it is important that any material shows good durability and constant performance over time. To test this, we performed repeat adsorption/desorption breakthrough cycles to ensure that there was no loss of performance for SAMHCP-Ag-3 over multiple cycles. Seven repeat breakthrough curves were measured with a $50: 50$ propane/propene mixture

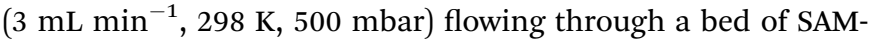

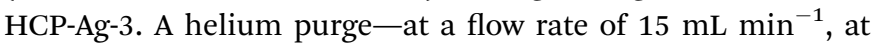
room temperature, for 10 hours-was used between cycles to ensure full desorption, with no other activation required. All seven breakthrough curves have identical propane and propene breakthrough times (Fig. 5). In fact, the same batch of SAMHCP-Ag-3 was used for well over 50 different breakthrough
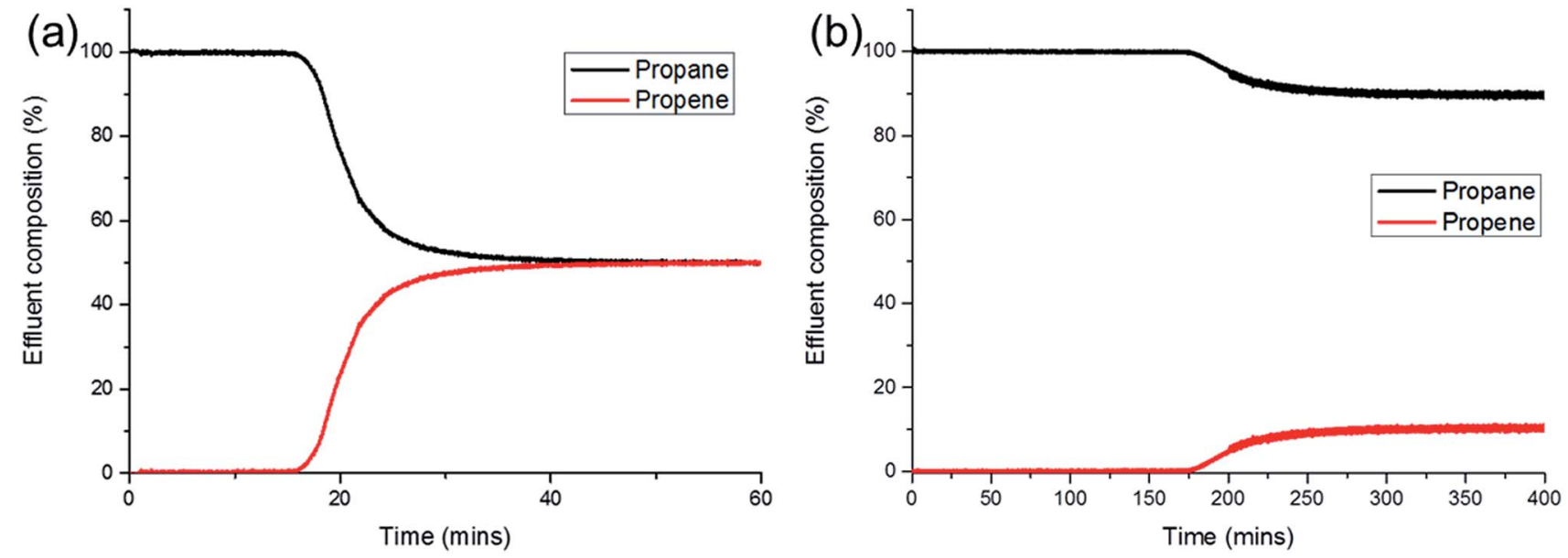

Fig. 4 Outlet composition of effluent derived from breakthrough curve of (a) $50: 50$ or (b) $90: 10$ propane/propene mixture flowing through

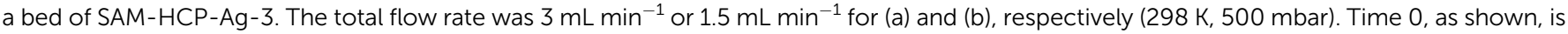
when propane first breaks through the column. 
cycles in total, with no apparent loss of performance. This demonstrates the excellent potential of this class of materials for practical applications.

\section{Conclusion}

A series of $\operatorname{Ag}(\mathrm{I})$ doped sulfonic acid functionalised HCPs were investigated for ethene/ethane and propene/propane separation. By varying the amount of Ag(I) in the HCPs, it was possible to tune the IAST selectivity and the gas uptake. The polymer SAM-HCPAg-3 showed the best potential for olefin/paraffin separations. SAM-HCP-Ag-3 also demonstrated excellent separation performance for propene/propane under flowing conditions as gauged by breakthrough curves measured at $298 \mathrm{~K}$ and at $318 \mathrm{~K}$. This polymer is able to separate propene and propane, with propene being preferentially adsorbed by the material, leading to the elution of $>99 \%$ pure propane. The material was stable over at least 50 separation cycles. HCPs have the advantage of being robust, cheap to synthesise, and scalable, and they could offer large potential energy savings for olefin/paraffin separations compared to traditional methods such as cryogenic distillation.

\section{Conflicts of interest}

There are no conflicts to declare.

\section{Acknowledgements}

The authors acknowledge funding from the Engineering and Physical Sciences Research Council (EPSRC) (EP/N004884/1, EP/ P034497/1), Newton Fund (EP/R003580/1), and the Leverhulme Trust via the Leverhulme Research Centre for Functional Materials Design.

\section{Notes and references}

1 D. S. Sholl and R. P. Lively, Seven Chemical Separations to Change the World, Nature, 2016, 532(7600), 435-437.

2 R. B. Eldridge, Olefin Paraffin Separation Technology a Review, Ind. Eng. Chem. Res., 1993, 32(10), 2208-2212.

3 R. T. Yang, Adsorbents: Fundamentals and Applications, WileyInterscience, 2003.

4 Z. Bao, S. Alnemrat, L. Yu, I. Vasiliev, Q. Ren, X. Lu and S. Deng, Adsorption of Ethane, Ethylene, Propane, and Propylene on a Magnesium-Based Metal-Organic Framework, Langmuir, 2011, 27(22), 13554-13562.

5 Y.-S. Bae, C. Y. Lee, K. C. Kim, O. K. Farha, P. Nickias, J. T. Hupp, S. T. Nguyen and R. Q. Snurr, High Propene/ Propane Selectivity in Isostructural Metal-Organic Frameworks with High Densities of Open Metal Sites, Angew. Chem., Int. Ed., 2012, 51(8), 1857-1860.

6 Y. He, R. Krishna and B. Chen, Metal-Organic Frameworks with Potential for Energy-Efficient Adsorptive Separation of Light Hydrocarbons, Energy Environ. Sci., 2012, 5(10), 9107.

7 J. E. Bachman, M. T. Kapelewski, D. A. Reed, M. I. Gonzalez and J. R. Long, $\mathbf{M}_{2}$ ( $m$-Dobdc) ( $\left.\mathbf{M}=\mathbf{M n}, \mathrm{Fe}, \mathrm{Co}, \mathrm{Ni}\right)$ MetalOrganic Frameworks as Highly Selective, High-Capacity
Adsorbents for Olefin/Paraffin Separations, J. Am. Chem. Soc., 2017, 139(43), 15363-15370.

8 Y. Chen, Z. Qiao, D. Lv, C. Duan, X. Sun, H. Wu, R. Shi, Q. Xia and $\mathrm{Z}$. Li, Efficient Adsorptive Separation of $\mathrm{C}_{3} \mathrm{H}_{6}$ over $\mathrm{C}_{3} \mathrm{H}_{8}$ on Flexible and Thermoresponsive CPL-1, Chem. Eng. J., 2017, 328, 360-367.

9 F. A. Da Silva and A. E. Rodrigues, Adsorption Equilibria and Kinetics for Propylene and Propane over 13X and 4A Zeolite Pellets, Ind. Eng. Chem. Res., 1999, 38(5), 2051-2057.

10 A. van Miltenburg, J. Gascon, W. Zhu, F. Kapteijn and J. A. Moulijn, Propylene/Propane Mixture Adsorption on Faujasite Sorbents, Adsorption, 2008, 14(2-3), 309-321.

11 J. Liu, E. M. Calverley, M. H. McAdon, J. M. Goss, Y. Liu, K. C. Andrews, T. D. Wolford, D. E. Beyer, C. S. Han, D. A. Anaya, R. P. Golombeski, C. F. Broomall, S. Sprague, H. Clements and K. F. Mabe, New Carbon Molecular Sieves for Propylene/Propane Separation with High Working Capacity and Separation Factor, Carbon, 2017, 123, 273-282.

12 A. Cadiau, K. Adil, P. M. Bhatt, Y. Belmabkhout and M. Eddaoudi, A Metal-Organic Framework-Based Splitter for Separating Propylene from Propane, Science, 2016, 353(6295), 137-140.

13 R.-B. Lin, L. Li, H.-L. Zhou, H. Wu, C. He, S. Li, R. Krishna, J. Li, W. Zhou and B. Chen, Molecular Sieving of Ethylene from Ethane Using a Rigid Metal-Organic Framework, Nat. Mater., 2018, 17, 1128-1133.

14 E. D. Bloch, W. L. Queen, R. Krishna, J. M. Zadrozny, C. M. Brown and J. R. Long, Hydrocarbon Separations in a Metal-Organic Framework with Open Iron(II) Coordination Sites, Science, 2012, 335, 1606-1610.

15 Y. Ye, Z. Ma, L. Chen, H. Lin, Q. Lin, L. Liu, Z. Li, S. Chen, Z. Zhang and S. Xiang, Microporous Metal-Organic Frameworks with Open Metal Sites and $\pi$-Lewis Acidic Pore Surfaces for Recovering Ethylene from Polyethylene off-Gas, J. Mater. Chem. A, 2018, 6(42), 20822-20828.

16 Y. Wang, Z. Hu, Y. Cheng and D. Zhao, Silver-Decorated Hafnium Metal-Organic Framework for Ethylene/Ethane Separation, Ind. Eng. Chem. Res., 2017, 56(15), 4508-4516.

17 G. Chang, M. Huang, Y. Su, H. Xing, B. Su, Z. Zhang, Q. Yang, Y. Yang, Q. Ren, Z. Bao and B. Chen, Immobilization of Ag(I) into a Metal-organic Framework with $-\mathrm{SO}_{3} \mathrm{H}$ Sites for Highly Selective Olefin-paraffin Separation at Room Temperature, Chem. Commun., 2015, 51(14), 2859-2862.

18 B. Li, Y. Zhang, R. Krishna, K. Yao, Y. Han, Z. Wu, D. Ma, Z. Shi, T. Pham, B. Space, J. J. Liu, P. K. Thallapally, J. J. Liu, M. Chrzanowski and S. Ma, Introduction of $\pi$ Complexation into Porous Aromatic Framework for Highly Selective Adsorption of Ethylene over Ethane, J. Am. Chem. Soc., 2014, 136(24), 8654-8660.

19 K. C. Kim, C. Y. Lee, D. Fairen-Jimenez, S. T. Nguyen, J. T. Hupp and R. Q. Snurr, Computational Study of Propylene and Propane Binding in Metal-Organic Frameworks Containing Highly Exposed $\mathrm{Cu}+$ or $\mathrm{Ag}^{+}$ Cations, J. Phys. Chem. C, 2014, 118(17), 9086-9092.

20 L. Tan and B. Tan, Hypercrosslinked Porous Polymer Materials: Design, Synthesis, and Applications, Chem. Soc. Rev., 2017, 46(11), 3322-3356. 